\title{
КЛИНИЧЕСКОЕ ТЕЧЕНИЕ ПЕРМАНЕНТНОГО НЕОНАТАЛЬНОГО САХАРНОГО ДИАБЕТА В СЕМЬЕ С ГЕТЕРОЗИГОТНОЙ МУТАЦИЕЙ В ГЕНЕ ИНСУЛИНА
}

\author{
Романенкова Е.М., Сечко Е.А., Кураева Т.Л.
}

ФГБУ «Национальный медицинский исследовательский центр эндокринологии» Министерства здравоохранения Российской Федерации, Россия, Москва

Ключевые слова: сахарный диабет, MODY, Maturity-Onset Diabetes of the Young, ген INS.

Введение. Неонатальный сахарный диабет (НСД) - это редкое, гетерогенное заболевание, которое характеризуется дебютом в возрасте от 6 до 18 месяцев жизни. Различают перманентный и транзиторный варианты заболевания. Известно более 25 генов, мутации в которых приводят к развитию НСД. Одной из частых причин перманентного НСД являются мутации в гене инсулина (INS). При гетерозиготных мутациях в данном гене нарушается процесс укладки молекулы проинсулина. Чрезмерное накопление в $\beta$-клетках проинсулина с неправильной структурой приводит к стрессу эндоплазматического ретикулума и преждевременному апоптозу $\beta$-клеток. Клинический случай. Ребенок от физиологической беременности, с нормальными росто-весовыми показателями при рождении. В первые месяцы жизни отмечалась плохая прибавка в весе. В возрасте 6 месяцев ребенок госпитализирован в стационар с проявлениями острой кишечной инфекции, при обследовании выявлена глюкозурия, гипергликемия до 24 ммоль/л, акетонурия. Установлен диагноз «Сахарный диабет 1 типа» (СД1), инициирована инсулинотерапия в суточной дозе 0,5 ед/кг.

В возрасте 1,2 лет проходила обследование в ФГБУ «НМИЦ эндокринологии», длительность заболевания 8 месяцев. При обследовании: рост 77.6 см (-0,36 SD), вес 10.5 кг, ИМТ 17,44 (0,14 SD). Гликированный гемоглобин 5,6\%, С-пептид 0,2 нг/мл, панкреатические аутоантиатела GAD, ICA, IA2, ZnT8 - отрицательные. Отмечалась низкая вариабельность гликемии, колебания от 4 до 9 ммоль/л на фоне инсулинотерапии в суточной дозе 0,4 ед/кг. Учитывая раннюю манифестацию заболевания, отрицательный титр панкреатических аутоантител, заподозрен НСД. По данным молекулярногенетического исследования в гене INS выявлен патогенный вариант в гетерозиготном состоянии c.94G>A (p.G32S), описан при НСД.

При повторном обследовании в ФГБУ «НМИЦ эндокринологии» в возрасте 4,5 лет, длительность заболевания 4 года: рост 108 см (0,63 SD), вес 20,0 кг, ИМТ 17,1 кг/м2 (1,2 SD). Гликированный гемоглобин 7,6\%, С-пептид 0,52 нг/мл, суточная доза инсулина 0,9-1,1 ед/кг.

У отца ребенка СД1 установлен в возрасте 9 месяцев, получает инсулин (суточная доза 1 ед/кг). На момент обследования (35 лет) гликированный гемоглобин 9,0\%. Из осложнений сахарный диабета (СД) выявлена препролиферативная ретинопатия. Стоит отметить низкую комплаентность пациента, отсутствие самоконтроля и нерегулярное введения инсулина. Проведено молекулярногенетическое исследование, выявлена аналогичная мутация в гене INS. 
Выводы. В описанной семье отмечается аутосомно-доминантный паттерн наследования, что характерно для НСД с гетерозиготными мутациями в гене инсулина. При обследовании девочки в возрасте одного года обращало на себя внимание стабильное течение СД с низкой вариабельностью гликемии без гипогликемий. По мере прогрессирования заболевания у ребенка отмечается рост HbAlс с увеличение дозы инсулина, однако истощения секреции С-пептида не отмечалось. У отца ребенка при длительности заболевания 34 года при низком самоконтроле из осложнений СД диагностирована только препролиферативная ретинопатия.

Таким образом, течение НСД в описанной семье характеризовалось аутосомно-доминантным наследованием, стабильным течением с постепенным прогрессированием заболевания. При диагностике неиммунного СД до 1 года жизни с аутосомно-доминантным типом наследования рекомендуется проведение молекулярно-генетическое исследование гена INS. 